\title{
Meaning and Understanding of School Mathematical Concepts by Secondary Students: The Study of Sine and Cosine
}

\author{
Enrique Martín-Fernández ${ }^{1 *}$, Juan Francisco Ruiz-Hidalgo ${ }^{1}$, Luis Rico ${ }^{1}$ \\ ${ }^{1}$ Department of Mathematics Education, Faculty of Education, University of Granada, Campus Universitario Cartuja s/n, 18011, \\ Granada, SPAIN
}

Received 18 November 2018 - Revised 5 April 2019 • Accepted 12 April 2019

\begin{abstract}
Meaning and understanding are didactic notions appropriate to work on concept comprehension, curricular design, and knowledge assessment. This document aims to delve into the meaning of school mathematical concepts through their semantic analysis. This analysis is used to identify and establish the basic meaning of a mathematical concept and to value its understanding. To illustrate the study, we have chosen the trigonometric notions of sine and cosine of an angle. The work exemplifies some findings of an exploratory study carried out with high school students between 16 and 17 years of age; it collects the variety of emergent notions and elements related to the trigonometric concepts involved when answering on the categories of meaning which have been asked for. We gather the study data through a semantic questionnaire and analyze the responses using an established framework. The subjects provide a diversity of meanings, interpreted and structured by semantic categories. These meanings underline different understandings of the sine and cosine, according to the inferred themes, such as length, ratio, angle and the calculation of a magnitude.
\end{abstract}

Keywords: meaning, non-compulsory secondary education, semantic analysis, understanding of a mathematical concept

\section{INTRODUCTION}

Trigonometry is a significant and integrating topic in high school mathematics curriculum due to its relevance in advanced mathematical thinking. It is a pillar not just for advanced mathematics but also for physics, geometry, and mechanics. It is "the precondition for understanding more advanced concepts and it is necessary for the formation of a mathematical language" (Dündar, 2015: 1380). In fact, trigonometry falls under the geometry content strand in the Common Core State Standards of Mathematics (National Governors Association Center for Best Practices, 2010). It follows from such relevance that students should be able to construct meaningful trigonometric concepts and procedures, essential for their learning experiences.

Trigonometry is also a part of mathematics that is difficult to understand by students. For this reason, low achievement on trigonometry is one of the cited indices to indicate a decrease in the university mathematics domain. Teachers often complain about how "students find trigonometry one of the hardest subjects in A-levels. They have difficulty with it as it becomes more abstract" (Challenger, 2009: 5). There are many explanatory factors to interpret this resistance, related to various circumstances such as its conceptual wealth, or its connections with a large diversity of phenomena and with other disciplines. The difficulty in understanding this content should also be attributed to the diverse types of problems involved, to its structural complexity and to the variety of its representative forms (Dündar, 2015).

This research is built on a semantic framework that analyzes the meaning of a content using three semantic categories: its conceptual structure, its systems of representation, and its sense (Bunge, 2008: 24-25). These three categories and their components are employed as analytical and interpretive tools to describe the meaning of a content (Martín-Fernández, Ruiz-Hidalgo, Rico, 2016).

(C) 2019 by the authors; licensee Modestum Ltd., UK. This article is an open access article distributed under the terms and conditions of the Creative Commons Attribution License (http://creativecommons.org/licenses/by/4.0/).

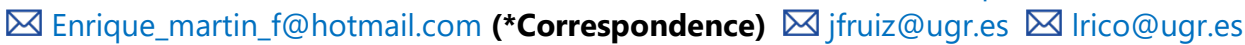




\section{Contribution of this paper to the literature}

- This paper tests the usefulness, convenience and adequacy of a semantic triad to study the understanding of students.

- This study integrates a semantic triad that provides with information on mathematical concepts.

- This paper identifies and characterizes the meanings of the sine and cosine that secondary school students show.

Understanding a mathematical content in depth involves providing its concepts and performing its procedures with coherent meaning, "to understand something means to assimilate it into an appropriate schema" (Skemp, 1987: 29). To understand mathematical contents is an important target in mathematics education.

This study is part of a research project on school mathematical concepts meaning and their understanding. Former works have examined the meaning of other mathematical concepts (Castro-Rodriguez et al., 2016; Fernández-Plaza et al., 2013). This paper introduces a descriptive study that concentrates on the meanings that a group of Spanish Non-Compulsory Secondary Education students (16-17 years-olds) associates with the notions of sine and cosine. We try to overcome a careless tradition: "there has been minimal interest in the study of student's trigonometry concepts because it is only a small part of the mathematics curriculum" (Yigit Koyunkaya, 2016: 1).

The aim of this paper is firstly to identify and characterize the meanings that a group of students attributes to the sine and cosine concepts of an angle. The meanings given by the answers come from their basic elements. Several meanings might be identified. The accuracy of the meaning and the mastery of each concept will be firstly established from its richness of elements and breadth of its relationships. Secondly, the data analysis of the provided answers will allow investigating and evaluating the way in which students understand these contents. It will also help specify and improve the study framework. Finally, we will test the usefulness, and adequacy of using semantic triads for describing the meanings attributed to the concepts and their understanding.

Researchers that have worked on trigonometric concepts meaning have provided evidences that confirm the difficulty of the subjects building and understanding them (Moore et al., 2016; Montiel \& Jácome, 2014; Moore \& Laforest, 2014; Paoletti et al., 2015; Thompson, Carlson, and Silverman, 2007). In fact, Moore (2012) stated, "teachers often do not construct meanings for trigonometric functions" (p. 75). The meaningful of mathematical concepts will also help teachers develop coherent mathematical concepts in their teaching. Besides, as it has been said by Thompson et al. (2007), it is relevant the coordination of different meaning categories and its components so as to build a coherent whole. Despite the fact that a variety of researchers have investigated trigonometric concepts understanding by secondary school students (Brown, 2005; Challenger, 2009; Demir, 2012; Marchi, 2012), we have not found researches that have explicitly concentrated on trigonometric concepts meaning by secondary school students basing on a semantic framework. Therefore, we intend to expand the limited current literature.

Summarizing, although some of the aforementioned researchers have already provided criteria for exploring the categories and the components of the meaning of a concept, we have the purpose of delving into the meaning of sine and cosine concept through a semantic triad, as expressed and understood by secondary school students.

\section{FRAMEWORK}

As it has been stated, understanding a mathematical content involves providing its concepts and procedures with a structured meaning. Identifying and characterizing the meanings expressed by a group of students about some mathematical content are not easy tasks in mathematics education. Theoretical and methodological approaches have been partially developed. There are several proposals built to investigate how to endow a mathematical content with meaning, in which a three semantic categories frame is used (e.g. Biehler, 2005; Radford, 2003; Sáenz-Ludlow, 2003; Steinbring, 2006; Vergnaud, 1990). These triads characterize aspects of the mathematical knowledge, and at the same time, they can be used as methodological tools to analyze the meaning of mathematical contents and their related understanding (Steinbring, 1998: 172).

In this paper we choose Frege's semantic triad (sign, sense and reference) to establish our meaning definition systems of representation, sense, and conceptual structure respectively). In other words, his triad includes the sign, a proper name, which expresses the concept; the reference or the concept itself; and the sense, which illuminates aspects and conditions of the reference which it satisfies (Frege, 1962: 37).

We have adapted and developed this description for school mathematical notions, concepts, and contents. We will use a three-categories framework to interpret the mathematical meaning shown by students, composed as follows: the conceptual structure, which includes the concept and the relation of this concept with other concepts; the systems of representation, which involve signs used to represent the concept and its relationships, and the sense, which contains modes of use which give sense to the concept. 
The goals of this work are to identify and characterize the meanings that a group of secondary school students group attributes to the sine and cosine of an angle; to inquiry how those students understand these concepts; and to test the convenience, usefulness, and adequacy of a semantic triad to describe the meanings attributed to those concepts and their understanding.

The research questions guiding the study are:

How do secondary school students express that knowledge through its conceptual structure, its representation systems and its sense?

What typologies of meaning regarding the sine and cosine of an angle do secondary school students provide?

\section{Conceptual Structure}

The term structure is used in a variety of fields, and it generally refers to an organized whole. A structure is generally considered "as a non-empty set together with relations, operations and distinguished elements" (Demopoulos, 1994: 213). In mathematics, Shapiro defines a structure as "the abstract way of a system, emphasizing the interrelationships among objects, ignoring any feature of them that not affect to the way in which they relate with others objects in the system" (1997: 74).

In this paper we utilize the term conceptual structure in a wider sense so that it encompasses several components: notions, concepts, properties, propositions, procedures and their relationships involved in a mathematical content. It determines priorities, and highlights connections; it shows the trajectories so as to organize the learning expectations; it provides references to establish the truth or false quality of a statement.

\section{Systems of Representation}

Learning mathematics involves working with signs, symbols and other representations. In that way, this study belongs to the tradition that considers a representation as any external thing that is utilized to stand for any other thing (Golding \& Kaput, 1996). Morgan and Kynigos (2014) point out that each representation creates meaning.

Representation systems are inescapable for expressing, generating and communicating the meaning of a concept. Depending of the representation used for a concept, different meanings may be identified.

Due to the systemic nature of a mathematical structure, each of its representations is encoded within a system. The different representation systems organize diverse experiences, highlight some properties and relationships and hide others (Golding \& Kaput, 1996). "The power and utility of the representations depend on their being part of a structured system, and on the degree of flexibility or versatility in what they can represent" (Golding \& Kaput, 1996: 400). In this work, by representation system we understand those combinations of signs and rules whose use transmits specific mathematical contents in a structured, operative and coherent way (Rico, 2009).

\section{Sense}

Mathematical concepts, structures and ideas help organize and give sense of phenomena. These phenomena are the roots of these mathematical ideas and they contribute to the development of the mathematical contents (Freudenthal, 1983). Phenomena are presented in a variety of problem situations, which are the source and may serve as contexts for this development (Van den Heuvel-Panhuizen, 2003, 2014). "These sites provide the context in which the learning of mathematics takes place so that both the meaningfulness and the utility of the mathematical ideas are ensured" (Lamon, 1995: 168). Biehler (2005) stated that different contexts provide differentiated senses for a mathematical concept (p. 61).

We consider sense when applying mathematical concepts and procedures in different contexts, which are the questions which the mathematical concept give answer -contexts-; when properly choosing the words for a concept -terms-, and so as to mention the settings in which they are involved -situations.

\section{BACKGROUND}

Although there have been multiple studies that present useful results associated with students' difficulties with this topic, more research is needed on students' meaning of trigonometric concepts (Moore \& Laforest, 2014; Yigit Koyunkaya, 2016).

Because studies about meanings of the trigonometry in secondary school students are limited, we underline the current results about the categories of the semantic triad, highlighting the existing literature about this issue. 


\section{Studies on Conceptual Structure}

Researches on the mathematical concepts structure by secondary school students have generated some information related to trigonometry. First, difficulties of the students stem from a weak knowledge of foundational concepts such as angles, measuring angles and the unit circle (Brown, 2005; De Kee, Mura \& Dionne, 1996; De Villier \& Jugmohan, 2012; Gur, 2009; Orhun, 2004; Thompson, 2007). Researchers emphasize the fact that students tend to describe trigonometric concepts in terms of procedures, but are unable to provide definitions of concepts in their own words or formulate their own knowledge and thus resort to memorize (Challenger, 2009; De Villier \& Jugmohan, 2012). Besides, results also illustrate that trigonometry is more strongly associated with the triangle, and to a lesser extent with the unit circle (Challenger, 2009; Demir, 2012; Marchi, 2012; Orhun, 2004).

Regarding the ideas involved in learning about trigonometry, whereas Brown (2005) describes the mathematical content and the ways in which students understand it, based on the connection between the triangle and the unit circle, Demir (2012) expands the model, including the trigonometric function. Besides, he states "it is difficult to find a firm framework for trigonometry understanding in the literature" (p. 16).

\section{Studies on Representation Systems}

Some studies have documented how students work with several representations when they deal with trigonometric ideas (Byers, 2010; Weber, 2008). Byers (2010) point out that there are six different themes to represent trigonometric notions including: "the right triangle, the trigonometric ratios, the trigonometric functions, the unit circle, the sinusoidal waveform and the vector" (p. 5). In this sense, Weber (2008) stated that there are only two main ways of presenting sine and cosine: ratios and functions.

Regarding secondary school students, the principal ideas of trigonometry are mediated through a mixture of algebraic representations such as ratios and formulae, graphical representations like triangles, circles or graphs (Challenger, 2009) and verbal representations such as definitions (Martín-Fernández et al., 2014). As far as these representations are concerned, they are unique to the topic (Sickle, 2011). Brown (2005) underlined that they are most often represented as coordinates of the terminal point on the unit circle, as directed distances from the horizontal and vertical axes on the unit circle, and as ratios between two sides of a right-angle triangle. MartínFernández et al. (2016) found that students also perform the sine and cosine of an angle by means of an angle, angle of a triangle and by the ratio of two any sides of a triangle. Finally, Marchi (2012) states that although there is no consensus about the ways to represent them, the right triangle, the unit circle, the graphs and the equations are presented somehow.

\section{Studies on Sense}

Main studies based on collection of textbooks, and on the responses of high school mathematics teachers and professors from universities have produced information on sense (Allen, 1977; Sickle, 2011; Hertel, 2013; Tavera \& Villa-Ochoa, 2016). A small part of this information is associated directly with secondary school students.

By turn of the twentieth century, trigonometry textbooks emphasized surveying, navigation and calculus (Sickle, 2011: 189). The content of the trigonometry courses from 1890 to 1970 in the Unites States and Canada has concentrated on working with triangles and problems such as those found on surveying, carpentry and ballistics (Allen, 1977). Tavera and Villa-Ochoa (2016) point out that nowadays, trigonometric functions are used to calculate the missing sides of a right angle triangle, and that textbooks use indiscriminately the terms function and ratio. Similarly, students initially perceive trigonometry as a set of procedures utilized for problems with triangles in Challenger's research (2009).

The larger study concerning the sense is authored by Hertel (2013). He expressed that the majority of the practical applications at the introductory level are dominated by the triangle. However, it is necessary to understand how trigonometry is positioned within the mathematics curriculum and its role in the modern sciences. Nowadays, although trigonometry is an important topic of secondary school, which is commonly used in daily life, but it is not positioned accordingly (Dogân, 2001). Kamber and Takaci (2018) defended that students "do not know exactly how trigonometry is used in practical situations" (p. 174). The contexts and situations, together with the role of the real-world building upon experiences, should be investigated and revised in trigonometry (Thompson, 2007). Finally, Hertel (2013) points out that there is a critical demand to extend this research to students that learn trigonometry.

\section{Summary}

On balance, previous researchers look into the meaning of the sine and cosine of secondary school students, but they mainly concentrate on one of the semantic categories of our framework. Whereas some of these studies focus 
on examining the trigonometric representations and how secondary school students link them (Marchi, 2012), others examine how secondary school students understand the concepts involved (Brown, 2005; Demir, 2012). Finally, others investigate the presence of trigonometry in current sciences and their relation to educational practices and modern curricula (Hertel, 2013). We have not found previous research on the connections between these three semantic categories in secondary school students. A goal of this study is to contribute to overcome that lack.

\section{METHODOLOGY}

This is a qualitative study based on the survey method. This method is used to collect data with the purpose of describing, interpreting and structuring the existing situation and developing possible explanations based on the chosen semantic framework (Fraenkel \& Warren, 2006). The sample is made up of a group of Grade 11 students. The instrument is a semantic questionnaire, designed by the researchers, grounded on the Frege's semantic categories for two trigonometric concepts: the sine and cosine of an angle. As a procedure, we use the content analysis.

\section{Participants and Settings}

The participants were 74 students (37 males and 37 females) in Non-Compulsory Secondary Education (16-17 years old) at a Spanish public secondary school. Prior to the study, according to the given information from the teachers involved, these pupils had been taught trigonometry and trigonometric functions pursuant to current regulation (MEC, 2007). All students were taking Mathematics-oriented subjects for Science and Technology track. They were chosen deliberately, depending on their availability. Three teachers, who had respectively thirty, seventeen and eleven years' experience, were responsible for their instruction. Through self-report and as observers, teachers asserted that they taught the topic using "traditional methods" and "mainly using the textbook". The textbook used in classes was "Matemáticas I para Bachillerato en la modalidad de Ciencias y Tecnología" (Vizmanos et al., 2008). Among teachers, only one of them occasionally utilized web applications. With regard to their instruction, it can be considered as "standard instruction". Most of the lesson time explaining, was devoted to the explanations of the topic and finally students were given enough time in order to do some exercises. Students were asked to perform eights tasks related to their trigonometry knowledge.

\section{Data Collection Tools}

We designed two semantic questionnaires presented as two different options, A and B, the first for the sine of an angle and the second for the cosine, based on the same questions.

The questionnaires were built up to gather the meaning of the concepts sine and cosine. Both of them allow us to find evidences showing what notions and properties the students are able to identify, how they represent and define them, what reasoning is used, and what terms, contexts, and situations they utilize to express its sense. In other words, the elements collected by the semantic questionnaires are drawings, terms, graphs, sentences, statements, relationships and reasoning, all of them descriptive data that exhibit traces of what notions and how the students have acquired the meaning of sine and cosine concepts. The questionnaire is the tool designed to collect the content elements (Rico, 2016).

In order to make a control validity of this instrument we apply a pilot study, which was conducted on 27 students of whom 13 answered questionnaire A, and 14 questionnaire B. To design this instrument, we took into account the considerations provided by an external consultant. The pilot test showed the adequacy and readability of the tasks.

The surveyed students were asked to answer eight items related to trigonometry, involving sine and cosine. The questionnaires included a variety of tasks in which students used verbal, numerical, analytic and graphical representations. Firstly, the items were adopted from Fi (2003) and Brown (2005), and analyzed, revised and modified so as to achieve our aims. The tasks were presented in a booklet. The students were required to draw pictures, explain concepts, generalize ideas, translate problems, and write their own ideas about questions related to the chosen concepts. The survey was conducted in a class session and students completed the items in less than 1 hour.

In this paper, we study the results of four items of both questionnaires, which show a set of tasks useful to explore the meaning ascribes by the student through the triad of semantic categories. 
Task 1-A. "Draw a picture in which it is showed $\sin \left(30^{\circ}\right)^{\prime \prime}$

Task 1-B. "Draw a picture in which it is showed $\cos \left(30^{\circ}\right)^{\prime \prime}$

Task 6-A and 6-B: "Draw a picture showing a difference between $\cos \left(30^{\circ}\right)$ and $\sin \left(30^{\circ}\right)$ ".

Task 2-A. "Explain in your own words sin $\left(30^{\circ}\right)$ "

Task 2-B. "Explain in your own words $\cos \left(30^{\circ}\right)^{\prime \prime}$

Task 8-A. "Write a problem in which you use the sine of $60^{\circ}$ "

Task 8-B. "Write a problem in which you use the cosine of $60^{\circ}$ "

Figure 1. Items of the questionnaires

\section{Task Design}

The aim of the item 2, about two concepts from trigonometry structure, is to evoke the basic elements of the sine and cosine of an angle. We identify terms, notions and definitions that students show when they explain in their own words the above mentioned concepts. Furthermore, we sought to explore if students distinguished the elements of a right triangle, using the most possible specific vocabulary and if they know how to express the studied concepts.

The first and sixth questions are connected with the representation systems. The main goal of these items is to keep a record of the variety of representations used by students and its complexity. The sixth question is also related to the discrimination of two similar concepts. This task allows students to utilize several systems of representation including the graphic and symbolic ones, given that the item asks students to do a drawing that shows some difference between the sine and cosine of the same angle.

The eighth question is related to the category sense. We intended to explore how the trigonometric concepts under study are used. We describe the contexts in which they appear, how pupils use the mathematical language, the terms associated with the studied concepts, and what situations they present. We sought to see if students understood a functional meaning for these trigonometric concepts and if they spontaneously showed the use of analyzed concepts with their everyday life. Additionally, the diversity of created tasks, their way of expression, and the made-up picture helped us gain insight into the students' meanings.

\section{Data Analysis}

The main worked method is analysis of content, which defines a set of strict categories and systematic procedures in order to analyze documents (Cohen, Manion \& Morrison, 2011: 563-564). “The process involves inductive reasoning, by which themes and categories emerge from the data through the researcher examinations and constant comparison" (Zhang \& Wildemuth, 2009: 2). "It seeks analyze data within a specific context of view of the meanings someone attributes to them" (Krippendorf, 1989: 403). The stages are described as follow.

The answers provide elements; these elements are the expressed facts, which work as information units. Researchers recognize relationships between the identified elements, giving rise to empirically founded components, subthemes. The themes emerge inductively from the subthemes. The precision, features and connections of subthemes and themes enable to achieve the most accurate meaning categories of the productions of students. Finally, we use auxiliary methods to show the data, which are tools to express the students' view, and we interpret them. Through this process, two researchers examine the results of the previous stages. The definition of themes, subthemes, and hypothesis about connections among them were verified.

\section{RESULTS}

In what follows five sections are presented. The three first sections characterize the answers corresponding to each category of meaning. The fourth section corresponds to the combinations of types of responses of the questions 1, 6 and 2, given that one answer to these items sometimes involves different subthemes and themes, linked to the systems of representation and conceptual structure, respectively. Finally, the last section presents the typologies of meaning expressed by the student group.

\section{First section: Conceptual Structure}

The questions 2-A and 2-B were designed to exemplify this section. The answers to these questions were classified together due to the similarity between the concepts sine and cosine. Table 1 displays the percentage of the types of responses associated with conceptual structure.

The first theme of response is associated to different ways of expressing a ratio such as: a formula, a relation, or using a variety of synonyms of the verb to divide up or to split. The second theme was determined basing on the students' reference to $a$ length as a cathetus, a height, a base, a side of a triangle, a segment or a coordinate. The third 
Table 1. Percentage of the types responses for questions $2 \mathrm{~A}$ and $2 \mathrm{~B}$

\begin{tabular}{llc}
\hline Themes & Subthemes & Percentage $\mathbf{N}=\mathbf{1 0 1}$ \\
\hline \multirow{3}{*}{ Ratio } & Proportion & $1.98 \%$ \\
\cline { 2 - 3 } & Ratio definition of sine and cosine in a right-angle triangle & $36.63 \%$ \\
\cline { 2 - 3 } & Relation of sides in a non-right triangle & $4.95 \%$ \\
\hline \multirow{4}{*}{ Length } & Sides of a right-triangle with hypotenuse 1 & $0.99 \%$ \\
\cline { 2 - 3 } & Side of a right-triangle with hypotenuse different to 1 & $0.99 \%$ \\
\cline { 2 - 3 } & Sides of a triangle & $0.99 \%$ \\
\cline { 2 - 3 } & Directed segments on a unit circle & $9.90 \%$ \\
\cline { 2 - 3 } & Directed segments of a circumference & $2.97 \%$ \\
\hline Value & Cosine as the x-coordinate and the sine as y-coordinate of a point of the unit circle & $0.99 \%$ \\
\hline Tool & Value of the sine and cosine & $11.88 \%$ \\
\hline Measurement & Ms a tool for solving problems & $1.98 \%$ \\
\hline Angle & Measurement & $4.95 \%$ \\
\hline Others & Sides of an angle & $8.91 \%$ \\
\hline
\end{tabular}

kind of response is showed when students write down a numerical value, for example: " 0.7 ", " $1 / 2$ "; when they point out that the sine or cosine of an angle is a "number" and when they express that it is a "value". In the fourth type of answer, students show the sine and cosine of an angle as a tool. It is included in this use by means of employing expressions like: "to solve unknowns", "to work out triangles". Besides, there are answers that show the sine and cosine as a measurement. It is recognized in expressions such as "half of the radius", in which the unit (radius) and the measuring (half) are expressed. Finally, a response was interpreted in the theme angle because the studied concepts were described with expressions such as "side of the angle" or "adjacent side of an angle". Most students related the sine and cosine with the right angle triangle and almost nobody makes mistakes when they name the different parts of it. The results show that the ratio is the main theme, and almost any participant considers the sine and cosine as a tool or as a proportion. Besides, forty percent of students failed the question. Finally, each response can involve diversity themes given that an answer includes various sentences.

\section{Second Section: Systems of Representation}

The first and sixth questions were designed to exemplify this category, which demands a graphic representation to show what students draw as the sine or cosine of an angle.

Triangle and circumference are the basic units of analysis. On the one hand, from the triangle, two kinds of responses appear to involve non-right triangle and right triangle. Although there is a wide variability of responses, and thus subthemes, finally, they mainly interpret the sine and cosine as ratio or length. On the other hand, the circumference is divided using segments and axis indistinctly. Then, participants utilize a point-segment, a central angle or a right angle triangle in order to eventually interpret in most cases the sine and cosine as angle, ratio or length. Furthermore, responses seldom include the value of the sought sine and cosine.

Table 2 displays the students' answers regarding representation as a meaning category. 
Table 2. Percentage of the types of responses to questions $1 \mathrm{~A}, 1 \mathrm{~B}$ and 6

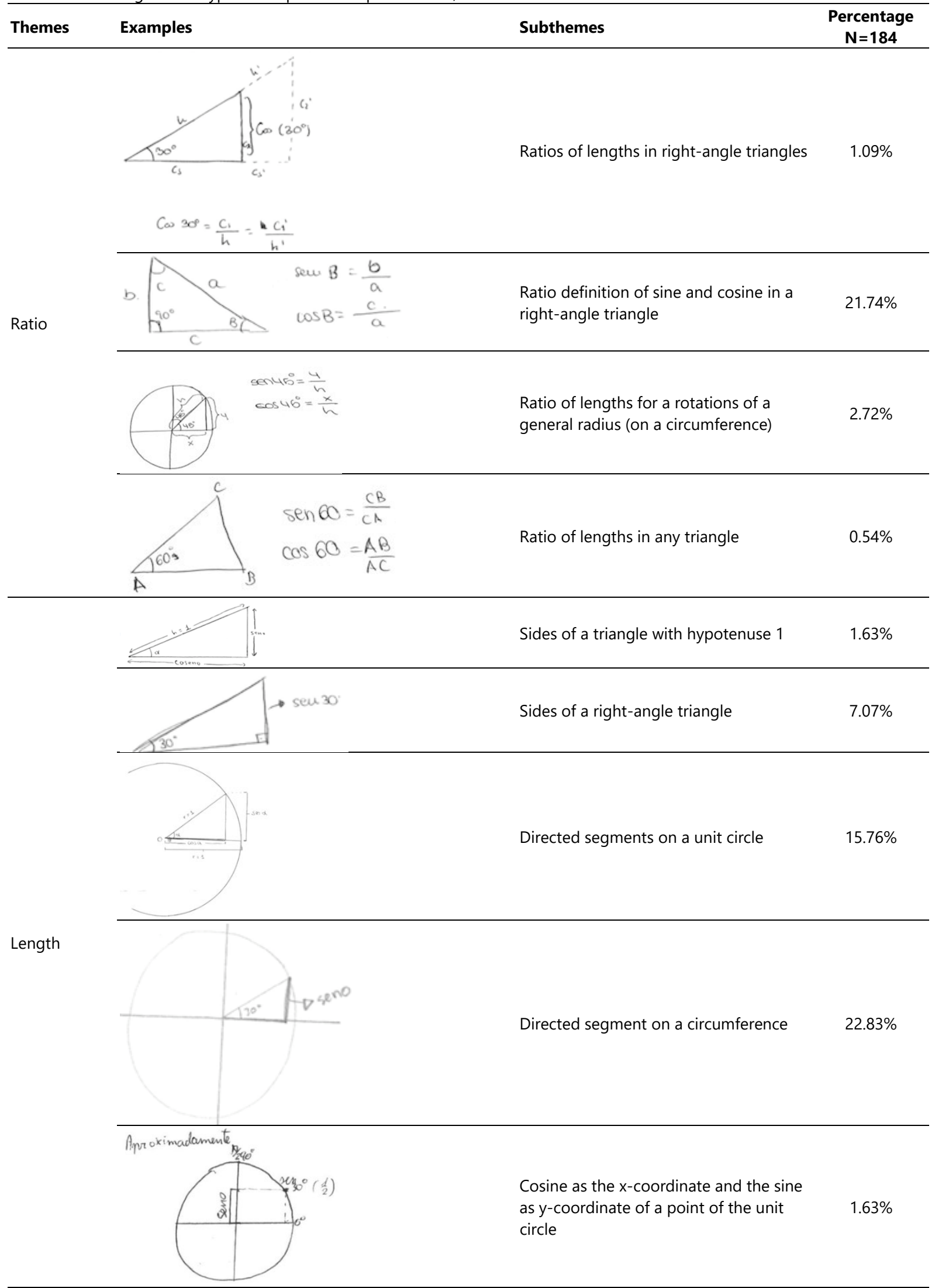


Table 2 (continued). Percentage of the types of responses to questions $1 \mathrm{~A}, 1 \mathrm{~B}$ and 6

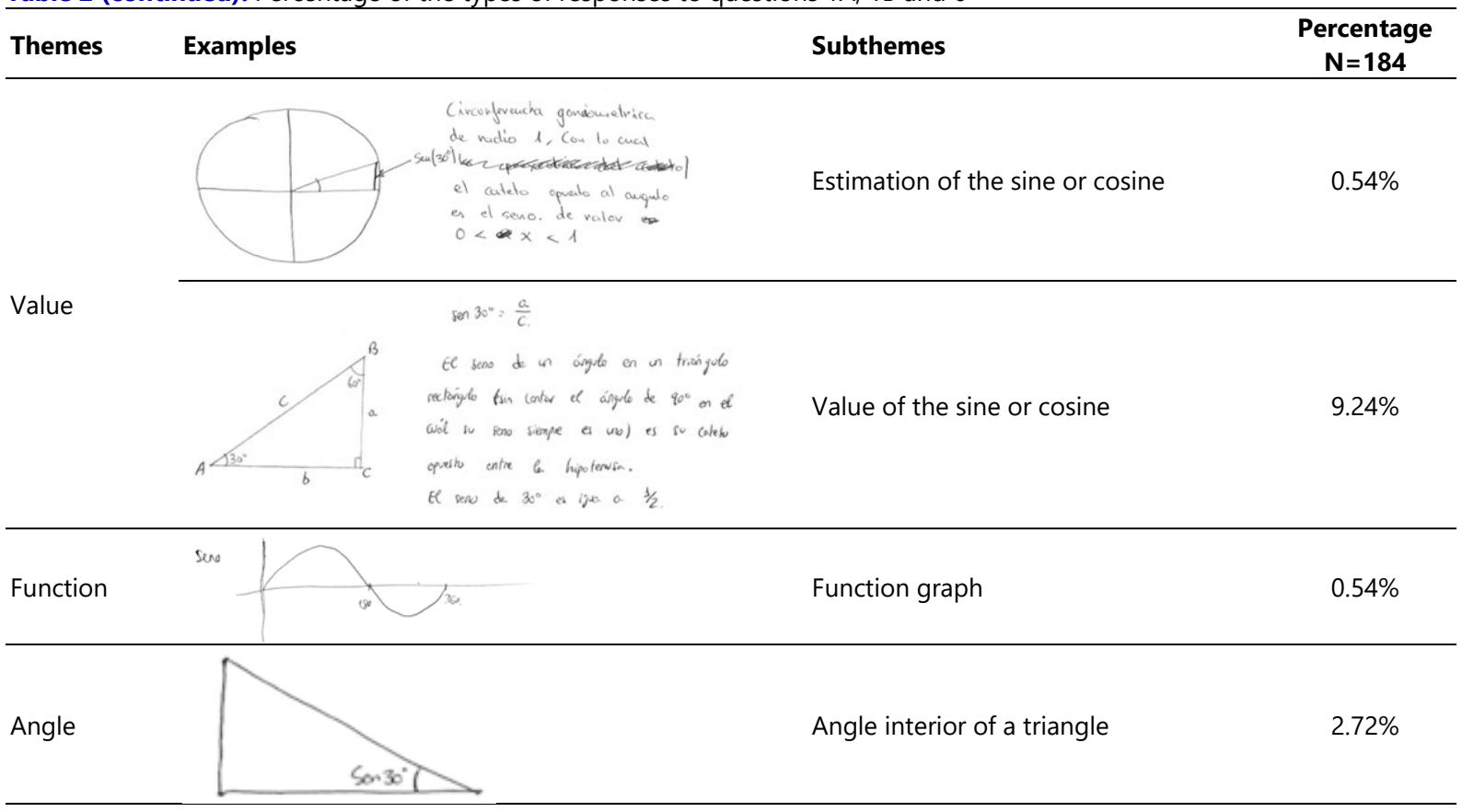

Considering all the answers, the notion of circumference appears in most of them, although the most frequent correct answer expresses the idea of ratio. In addition, the findings also show that subjects rarely refer to them as a function. Lastly, there are answers that involve more than two themes, as it can be seen for instance in the subtheme "Ratios of lengths in right-angle triangles", whose response can be included in the subtheme "Sides of a right-angle triangle" as well.

\section{Third Section: Sense}

The eighth question asks pupils to pose a problem where the sine or cosine of $60^{\circ}$ must be used. We distinguish two main themes in the obtained responses.

Indirect measurement of a magnitude: A response belongs to this theme when the unknown/s are a distance or an angle, for whose knowledge it is necessary to calculate the sine or cosine of an angle.

Although sine and cosine are used to calculate angles, volumes or areas, these applications barely appear. Besides, although some answers require calculating an angle, the cosine or sine are rarely used to find it out, and thus it is only needed to add up the angles of a triangle and to consider that the angles in a triangle sum $180^{\circ}$.

Another point worth mentioning here is that in order to solve the problem, it is only necessary to know the definition of the trigonometric ratios in the right triangle. Thus, few of these problems are solved using the relations and properties of the sine or cosine. An example is shown in Figure 2.

A student went zip-lining from a mountain using a rope that measures $200 \mathrm{~m}$. When he reached the ground, he checked that the stick that held the rope forms an angle of $60^{\circ}$ with respect to the ground and to the rope. How tall was the mountain from which he went zip-lining?

Figure 2. Example of response offered by a student

Computation of the sine and cosine of an angle: In this theme two subthemes appear: a) Calculate the trigonometric ratios of an angle, given the trigonometric ratio of another, and b) Find the value of an expression in which the studied concepts are involved.

A statement was interpreted as being in the sense a) if it includes a question in which you need to use the properties of trigonometric ratios so as to find out a value. An example answer for this subtheme is "knowing the trigonometric ratios of the angle of $30^{\circ}$, find the cosine of $60^{\circ}$ ". It should be noted that all responses of students were related to the angles of the first quadrant.

The option $b$ ) is associated with responses that involve substituting a parameter using an angle and remember perfectly some values of the sine or cosine. It includes answer such as: "solve: $\sin 2 x$ where $x=30^{\circ \prime}$. Similarly, in the productions only angles of the first quadrant appeared. 
Table 3. Percentage of themes expressed by the answers to question $8 \mathrm{~A}$ and $8 \mathrm{~B}$

\begin{tabular}{llc}
\hline Themes & Subthemes & Percentage $\mathbf{N}=\mathbf{7 7}$ \\
\hline \multirow{2}{*}{ Indirect measure of a magnitude } & Angles & $5.19 \%$ \\
\cline { 2 - 3 } & Length & $70.13 \%$ \\
\cline { 2 - 3 } & Angles and length & $6.49 \%$ \\
\hline Computation of the sine and cosine of an angle & & $9.09 \%$ \\
\hline Without answer & & $9.09 \%$ \\
\hline
\end{tabular}

All the responses to this question are related to a triangle. Thus, problems related to trigonometric functions or unit circle and their applications do not occur. We also indicate that they do not propose any problem in which it was required to solve an identity, or a trigonometric equation. Therefore, this kind of tasks may be considered somehow complicated from a mathematical point of view. This would imply that the students have not understood the variety of senses of the sine and cosine.

Finally, the majority of responses pose a question in an educational setting. Any response includes an angle of depression. Specific terms name objects that are related by means of well-known links between the objects. The terms used by pupils were: roof, post, firefighter, tower, lamppost, statue, tree, cities, ladder, building, house, balloon, lighthouse, mountain, rope, road, radio station, kite, and shadow.

Furthermore, we illustrate the most common situations (i.e. those with a percentage higher than $5 \%$ ) that are included in the previous themes.

Table 4. Situations of the types of responses

\begin{tabular}{lc}
\hline Situations & Percentage $\mathbf{N}=\mathbf{7 7}$ \\
\hline The height of an object & $14.29 \%$ \\
\hline The distance to an object & $19.48 \%$ \\
\hline Finding unknowns of a triangle & $14.29 \%$ \\
\hline Distance of a shadow & $5.19 \%$ \\
\hline Distance between two cities & $5.19 \%$ \\
\hline Calculating the sine or cosine of an angle & $7.79 \%$ \\
\hline
\end{tabular}

\section{Fourth Section: Combinations of Themes in Items 1, 6 and 2}

In this section we classify the individual responses depending on the combinations of themes that appear in them. There are student answers that involve diverse themes. These productions may imply various meanings. Table 5 shows percentages for themes and their combinations, as expressed by students in their individual answers to questions 1, 6 and 2. Some combinations present a low percentage. We show in Table 5 those whose percentage is higher than $2 \%$.

Table 5. Percentage of responses which includes combinations for question 1, 6 and 2

\begin{tabular}{|c|c|c|c|}
\hline $\begin{array}{l}\text { Number of } \\
\text { themes }\end{array}$ & $\begin{array}{l}\text { Themes and their } \\
\text { combinations }\end{array}$ & Example & $\begin{array}{c}\text { Percentage } \\
\mathrm{N}=222\end{array}$ \\
\hline \multirow{3}{*}{ One single theme } & Quotient & $\begin{array}{l}\text { El seno de } 45^{\circ} \text { es la division entre el cateto oquesto } \\
\text { ente lu hipotenusa en un tiangulo zectangulo. } \\
\text { (The sine of } 45^{\circ} \text { is the division between the opposite leg and the } \\
\text { hypotenuse in a right triangle) }\end{array}$ & $23.32 \%$ \\
\hline & Length & 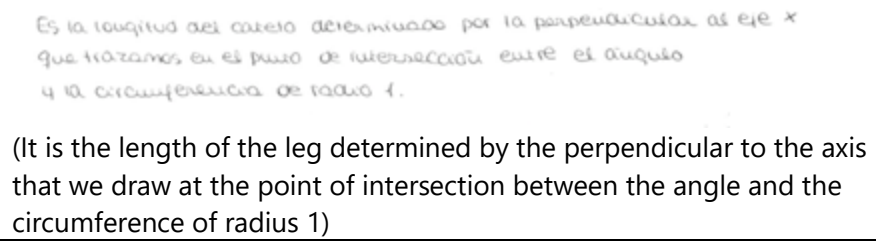 & $28.70 \%$ \\
\hline & Angle & & $4.48 \%$ \\
\hline
\end{tabular}


Table 5 (continued). Percentage of responses which includes combinations for question 1, 6 and 2

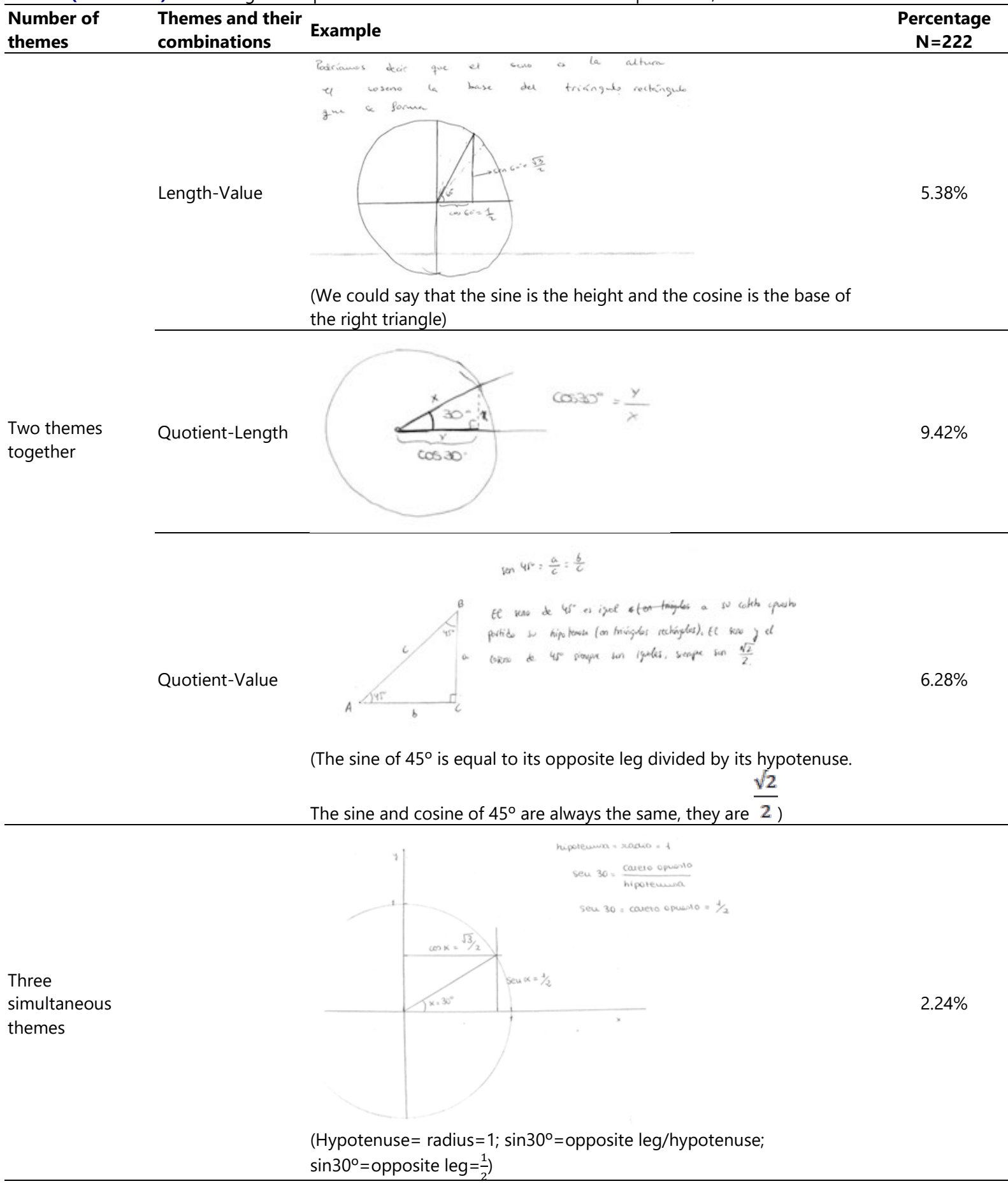

\section{Fifth Section: Typologies of Meaning}

After considering in isolation the themes and subthemes by categories, we have regarded their most frequent combinations and identified the triads presented jointly by each student. These combinations, empirically observed according to semantic categories, show a variety of meanings expressed by the student group for these concepts. To infer that information, we built a contingency table, which summarizes the relationships and interactions between the most frequent themes. 
Table 6. Table the contingency with the percentage of themes

\begin{tabular}{|c|c|c|c|c|c|}
\hline \multirow{2}{*}{\multicolumn{3}{|c|}{ Conceptual structure }} & \multicolumn{3}{|c|}{ Systems of representation } \\
\hline & & & \multirow{2}{*}{$\begin{array}{c}\text { Ratio } \\
17.07 \%\end{array}$} & \multirow{2}{*}{$\begin{array}{l}\text { Length } \\
19.51 \%\end{array}$} & \multirow{2}{*}{$\begin{array}{l}\text { Value } \\
5.69 \% \\
\end{array}$} \\
\hline & & Indirect measure of a magnitude & & & \\
\hline Ratıo & Sense & Computation of the sine and cosine & $3.25 \%$ & $1.62 \%$ & $0.8 \%$ \\
\hline Length & Sense & Indirect measure of a magnitude & $4.06 \%$ & $17.07 \%$ & $2.43 \%$ \\
\hline \multirow{2}{*}{ Value } & \multirow{2}{*}{ Sense } & Indirect measure of a magnitude & $4.06 \%$ & $6.50 \%$ & $4.06 \%$ \\
\hline & & Computation of the sine and cosine & $0.8 \%$ & $0.8 \%$ & $0.8 \%$ \\
\hline
\end{tabular}

Note. $11.39 \%(=14 / 123)$ of the responses are not included in table 6 because they do not consist of all elements of the semantic triad

Each of these triads show a specific type of meaning, according to the facts and components collected in the responses. As it can be seen, most of the options obtain a very low percentage of answers. We will not consider triads with percentages lower than $15 \%$, hence only three prevalent groupings, with highest percentages will be considered as prototypes of meaning, as shown by these student answers.

The themes of the contingency table are represented by the vertexes of a triangle and schematized as in Figure 3. They are identified as follow: top vertex -conceptual structure-, lower left vertex -systems of representation-, lower right vertex -sense.
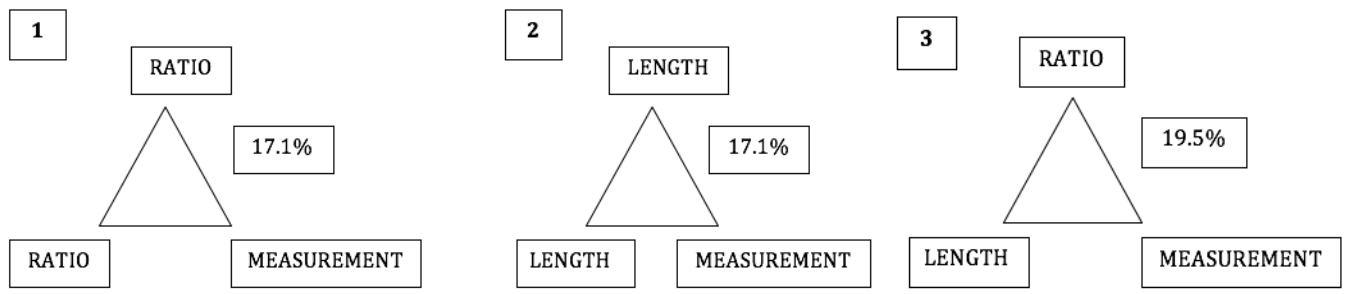

Figure 3. Prototypes of the meaning

Historically, two ways of measuring angles have been used and preferably developed: the "ratio system" that uses ratio length, and the "line system", using circumference (Sickle, 2011). Each of these meanings shows a proper way of understanding the sine and cosine notions, which is described by means of their themes.

With regard to the first meaning, schematized in triangle 1, the sine and cosine of and angle are defined and represented as ratio. This ratio is used to calculate a indirect measure of a magnitude. Ratio notion prevails in this trigonometric meaning prototype, which might be mainly related to the ratio system (Sickle, 2011).

As far as the second meaning (triangle 2) is concerned, it requires that a length, related to the calculation of an indirect measure of a magnitude, characterizes the analyzed concepts. Length of a bounded line, or segment, prevails in this trigonometric meaning prototype, which might be chiefly associated with the line system (Sickle, 2011).

In the third prototype meaning, students emphasize the connections between the "ratio system" (definition) and "line system" (representation) (Sickle, 2011) and it is also utilized to obtain an indirect measure of a magnitude. These subjects have clearly highlighted both systems.

Other meanings expressed by the students are localized in the contingency table by means of the triads of identified categories, together with their percentages. There are also students who leave questions unanswered, which are not analyzed in this paper.

\section{DISCUSSION}

\section{Semantic Triad: Conceptual Structure, Representation Systems and Sense}

The data corresponding to the first meaning category are collected from the answers to the second item (see Figure 1). These responses are not consistent with Brown's (2005) results, given that students do not only express the sine and cosine of an angle as length or ratio but also as value, measuring, tool and angle. Most participants understand these notions as a ratio, since most answers are related to derivative terms of "divide". Thus, these findings are not aligned with that of Kamber and Takaci (2018), for whom the sine was defined by a minority of students as a ratio in a right angle triangle. Besides, some responses included numeric values and terms as "value" or "result". It appears that the range of values of the sine and cosine is known because all the values proposed by students were ranged between -1 and 1 . There are also a small number of productions that have been linked to an instrumental character given that they include a reflection of the usefulness of studied concepts. Besides, a minority of responses is related to a length measure or an angle. Finally, the participants do not identify these concepts with 
the idea of proportion, which appears incidentally, nor with the notion of coordinate of the sinusoidal function. Obviously, if its conceptual structure is not well understood by students, it will be hard to teach other concepts related to them.

Knowing the history of trigonometry education will serve as a partial guide for mathematics educators and researchers of mathematics education to suggest actions (Sickle, 2011). Therefore, based on the history of the teaching of trigonometry, we conjecture the understanding of this first category by a right use of five fundamental notions: angle, ratio, right triangle, circumference and trigonometric functions. These notions are linked among them and originate various relationships (Martín-Fernández et al., 2016). Angles, ratios and circumference are related on account of the "line system", which defines the trigonometric ratios of an angle as line segments of a circumference, and it was originated from the ancient Greek and Arab conceptions of trigonometry (Maor, 1998). By the turn of the twentieth century, in secondary schools, trigonometric ratios were defined using real numbers arguments, "the ratio system", in which angles, ratios and right triangle are associated and trigonometric ratios are expressed as an a-dimensional ratio of sides of a right triangle (Sickle, 2011). Nowadays in many countries, the most commonly used approach to introduce the trigonometric ratios is the "ratio system". However, from a curricular perspective, if we define trigonometry based on how this term is currently used, trigonometry refers to the study of measuring the pertaining angles, triangles or functions (Fanning, 2016).

According to the second category of meaning posed in the first and sixth questions, and in contrast to the first category, most of the surveyed students mainly represent the sine and cosine of an angle as a length. So, different items may imply and emphasize different themes and inferences about the understanding of the involved notions.

The themes for the representation system category are similar to those just mentioned for the previous category. Students understand how to represent the studied concepts by means of a ratio, length, value, and angle, but it seems that students were not able to relate the sine and cosine to the trigonometric functions as well. On the other hand, a great number of students tend to represent the unit circle without measurement, making mistakes. Moreover, the unit circle generally acts as a fixed icon, which at the end it was not used to represent and understand the sine and cosine of an angle. Consistent to Challenger (2009), we interpret that students are not aware of the variety of the representation systems of the studied concepts. Students should understand their implications, advantages and drawbacks.

Related to the third category, students express problems and tasks associated with two different senses: indirect measure of a magnitude and computation of the sine and cosine. The sense of the studied concepts is mainly understood as a device to solve triangles; in particular student responses are directed to find out the distance of two cities, the height of a statue from its shadow, to determine the length of a flagpole, etc., involving fundamentally distances, angle of elevation and height. Nevertheless, they are limited to apply the "ratio system" to solve triangles at the first quadrant so that the variety of problems posed by students was scarce, and few students used the law of sine and cosine. It seems that multi-step problems, calculating the measurement of an angle given the measurement of two sides, modeling periodic phenomena such as vibrations and planetary orbits, are not known as problems for students. In contrast to Kamber and Takaci's (2018) study, student responses stay at triangle trigonometry. It might be because the definition of the sine and cosine using the unit circle is more generalizable and it requires more abstraction. Hence, the connections between the "ratio system" and "line system" are not adequately established. These answers can also be due to the instruction received by the students, even though the syllabus includes the identification, study, representation and interpretation of real tasks of trigonometric functions. It seems that it is necessary to present tasks more related to the modern sciences in order to position trigonometry correctly in secondary education. Furthermore, sense is the main missing category considering the $12 \%$ of responses that does not include any of them. Thus, we detect a gap between the understanding of both concepts and more attention to this issue should be required. When participants did not know how to express verbal problems, they utilized drawings to visually clarify their statements. This result corresponds with Sevimli and Delice's investigation (2012).

Consistent with Thompson's (2007) and Kamber and Takaci's (2018) studies, we recognize a scarce connection between the studied concepts with the real life and everyday mathematics of the lived-in experiences of children. In contrast with Allen (1977), navigation, surveying, carpentry and ballistics are not the predominant topics in trigonometry at the introductory levels of trigonometry in our data. The findings show that calculating the distance to an object is the most popular phenomenon among secondary school pupils. They should perceive the need of this topic for their future profession, so that they would be more motivated by the study of trigonometric concepts.

On the whole, this analysis provides useful information to design and plan the didactic materials in order to implement them in school mathematics. Each category includes a variety of themes and elements of content which will be taken into account by teachers. The predominance of some of them gives teachers information to enrich their students' meanings. Obviously, if students master a higher variety of themes, their meanings will be more complete and coherent. 


\section{Typologies of Meaning}

Eighty-eight percent of the students' responses have expressed their understanding of the concepts sine and cosine of an angle, based on a coherent meaning notion, supported by the chosen three categories as semantic framework. Fifty-three percent of answers have revealed their meaning utilizing ratio, length and indirect measure of a magnitude. Most of them have explained their meanings using the themes of ratio and length, both balanced. Some students understand these concepts of several ways.

Taking into account the prototypes of meaning, we may conclude that the group of secondary school students do not possess a prevalent meaning of the studied concepts. In prototypes of the first and second meaning, they use as representation the one coincident with the conceptual structure in the definition; only in the third prototype there is a percentage of students that clearly distinguish between definition and representation systems, which provides a greater richness of meaning and shows a better understanding of these notions. We believe that these results are due to the lack of the connection between the "ratio system" and "line system", and our syllabus. In our syllabus, both systems are taught in mathematics in two school years and the teachers who participated in this study introduced them at the same time. Consequently, "ratio system" and "line system" are predominant in student responses, and the same percentage is obtained in the first and second prototype of meaning. However, more lessons should focus on the connections between both systems, so that students are given more opportunities to enrich the meaning of the studied concepts. Emphasis on connections between "ratio system" and "line systems" may avoid fragmented understanding of the sine and cosine. Finally, all the prototypes concentrate on the indirect measurement of a magnitude. It seems that even although "line system" is predominant in a prototype of meaning, the kind of problems posed by students are typical of the "ratio system". Extra attention should be given to the connections with problems involving others themes in math classes. Finally, supporting understanding of the analyzed concepts appears to be not only an issue of supporting understanding of concepts such as angles, periodicity, properties learnt by heart, connecting different periodic representations (Kamber \& Takaci, 2018, p. 174; DeJarnette, 2018: 417) but also an issue of connecting categories of meaning and possessing a variety of meanings. Providing such relationships and a diversity of meanings has the potential to understand school mathematical concepts.

\section{CONCLUSION}

Understanding mathematical content involves using its concepts and working its procedures in a meaningful way. As we argued, the understanding of a school mathematical content could be established within a semantic framework suitable to describe and interpret its meaning.

The framework has been tested with the concepts of sine and cosine of an angle with a group of secondary schoolchildren through a survey, a semantic questionnaire as it has been described. In this manner, an approach on understanding of school mathematical concepts has been exemplified and contrasted. This is a first result that has been obtained from the study that frames this work.

A second specific result was achieved when the surveyed students characterized three different meanings for the concepts of sine and cosine. These modes are differentiated by the themes chosen to define, to represent and to use these concepts.

The triad works as a three-components tool for identifying meanings of a school mathematical concept. Students with the elements of their productions have shown several of these meanings that we have interpreted and characterized in terms of its themes within semantic categories. Accordingly, this research has developed arguments and has provided reasons in order to improve our knowledge of mathematics concept understanding by students, and it has also contributed to establish a method for its characterization. Our conjecture holds that when students have been in contact with specific mathematical notions, and have received training about them, they understand and learn them, strongly or weakly, use them and express them with a meaningful intention. Different students reach different developments, but their interpretative richness in each case may be identified from its content elements, and it can be described by the themes and structured by the meaning categories and their relationships. In fact, the combinations of the meaning categories expressed by students provide us with information about what each one has understood and what should be improved. Secondary school students are not aware of the basic elements of the studied concepts and their relationships. An incomplete meaning of a concept may involve difficulties for its understanding, and thus for teaching other related mathematical topics and disciplines.

Data were gathered with one semantic questionnaire, and from a natural group of secondary school students involved. As an exploratory study, we recognized its limitations. Our data came from a single semantic questionnaire, and from a group of secondary school students involved which were taught in a determined way. For that reason, we have followed a descriptive and interpretative methodology, trying to explain and understand all the gathered information, connecting with the existing results in the literature and choosing the wider 
explanations, with the current validity criteria in these kind of exploratory studies (Cohen, Manion \& Morrison, 2011).

Acknowledging these conditions, this study gives a step forward in a wider project whose goal is to deepen and gain insight into the meaning of school mathematical concepts. Future researchers may be interested in investigating students' understanding of other concepts or in exploring the relationships between semantic categories expressed by students so that they acquire a higher level of understanding of these concepts. We expect to follow on this general semantic frame to interpret the understanding of school mathematical concepts, contributing to the development of student mathematical knowledge and teacher professional competencies.

\section{ACKNOWLEDGEMENTS}

This study was developed within the framework of the National I+D+I Plan through project EDU2015-70565$\mathrm{P}$, entitled "Procesos de aprendizaje del profesor de matemáticas en formación, financied by the Spanish Ministry of Science and Technology and with the help of the group of Didactic of Mathematics Numerical Thinking, FQM193 of 3rd Andalusian Research Plan (PAIDI).

The research reported here was financially supported by "La Consejería de la Junta de Andalucía" and it is part of the doctoral dissertation of one of the authors.

\section{REFERENCES}

Akkoc, H. (2008). Pre-service mathematics teachers' concept images of radian. International Journal of Mathematical Education in Science and Technology, 39(7), 857-878. https:/ / doi.org/10.1080/00207390802054458

Allen, H. D. (1977). The teaching of trigonometry in the United States and Canada: A consideration of elementary course content and approach and factors influencing change, 1890-1970 (Unpublished doctoral dissertation), The State University of New Jersey, New Brunswick, NJ.

Biehler, R. (2005). Reconstruction of Meaning as a Didactical Task: The Concept of Function as an Example. In Kilpatrick J., Hoyles C., Skovsmose O., Valero P. (Eds), Meaning in Mathematics Education. Mathematics Education Library (vol 37, pp. 61-81). New York, NY: Springer. https:/ / doi.org/10.1007/0-387-24040-3_5

Brown, S.A. (2005). The trigonometric connections: Students' understanding of sine and cosine (Unpublished doctoral dissertation), Illinois State University, Illinois, IL.

Bunge, M. (2008). Tratado de Filosofía. Semántica I, Sentido y referencia. Barcelona, Spain: Gedisa Editorial.

Byers, P. (2010). Investigating trigonometric representations in the transition to college mathematics. College Quarterly, 13, 2, 1-10. Retrieved from http:/ / collegequarterly.ca/2010-vol13-num02-spring/byers.html

Castro-Rodríguez, E., Pitta-Pantazi, D., Rico, L., \& Gómez, P. (2016). Prospective teachers' understanding of the multiplicative part-whole relationship of fraction. Educational Studies in Mathematics, 92(1). https:/ / doi.org/10.1007/s10649-015-9673-4

Challenger, M. (2009). From triangles to a concept: a phenomenographic study of A-level students' development of the concept of trigonometry (Unpublished doctoral dissertation), Warwick University, UK. Retrieved from http://wrap.warwick.ac.uk/1935/1/WRAP_THESIS_Challenger_2009.pdf

Cohen, L. Manion, L., Morrison, K. (2011). Research Methods in Education, Routledge, London. UK.

Common Core State Standards Initiative. Mission statement [Internet]. 2010 [cited 2015 Oct 5]. Available from: http://www.corestandards.org/. District of Columbia: The Council of Chief State School Officers and National Governors Association Center for Best Practices.

De Kee, S., Mura, R., \& Dionne J. (1996). La comprensión des notions de sinus et de cosines chez des élèves du secondaire [Understanding the notions of sine and cosine in high school students]. For the Learning of Mathematics, 16(2), 19-22. Retrieved from https://flm-journal.org/Articles/ 5607DD229F6EE053055D3F415A7F74.pdf

De Villiers, M., \& Jugmohan, J. (2012). Learners' conceptualisation of the sine function during an introductory activity using sketchpad at grade 10 level. Educ. Matem. Pesq., São Paulo, 14(1), 9-30. Retrieved from https:/ / revistas.pucsp.br/index.php/emp/article/viewFile/8750/6826

DeJarnette, A. F. (2018). Students' Conceptions of Sine and Cosine Functions When Representing Periodic Motion in a Visual Programming Environment. Journal for Research in Mathematics Education, 49(4), 390-423. https://doi.org/10.5951/jresematheduc.49.4.0390

Demir, O. (2012). Students' concept development and understanding of sine and cosine functions (Unpublished doctoral dissertation), Amsterdan University, Amsterdam, The Netherlands. Retrieved from https:/ / esc.fnwi.uva.nl/thesis/centraal/files/f107257570.pdf 
Demopoulos, W. (1994). Frege, Hilbert, and the conceptual structure of model theory. History and Philosophy of Logic, 15(2), 211-225. https:/ / doi.org/10.1080/01445349408837233

Dogân, A. (2001). A research on misconceptions and mistakes of the students and their attitudes towards the trigonometry subjects which are teaching in the highschools (Unpublished doctoral dissertation), Selçuk University Institute of Sciences, Konya: Turkey.

Dündar, S. (2015). Mathematics Teacher-Candidates' Performance in Solving Problems with Different Representation Styles: The Trigonometry Example. Eurasia Journal of Mathematics, Science E Technology Education, 11(6), 1379-1397. https:/ / doi.org/10.12973/eurasia.2015.1396a

Fanning, J. D. (2016). Student responses to instruction in rational trigonometry. In Tim Fukawa-Connelly, Nicole Engelke Infante, Megan Wawro and Stacy Brown (Eds), Proceedings from 19th Annual Conference on Research in Undergraduate Mathematics Education, (pp. 741-751) Pittsburgh: PA.

Fernández-Plaza, J. A., Rico, L., \& Ruiz-Hidalgo, J. F. (2013). Concept of finite limit of a function at a point: Meanings and specific terms. International Journal of Mathematical Education in Science and Technology, 44(5), 699-710. https:/ / doi.org/10.1080/0020739X.2013.805887

Fi, C. (2003). Preservice secondary school mathematics teachers' knowledge of trigonometry: subject matter content knowledge, pedagogical content knowledge and envisioned pedagogy (Unpublished doctoral dissertation), University of Iowa, Iowa. Retrieved from https: / /ir.uiowa.edu/cgi/ viewcontent.cgi?article $=4936 \&$ context=etd

Fraenkel, J. R., \& Warren, E. A. (2006). How to Design and Evaluate Research in Education. Newyork: McGraw-Hill.

Frege, G. (1962). Über Sinn und Bedeutung. [About sense and meaning] In G. Patzig (Ed.), Funktion, Begriff, Bedeutung. Fünflogische Studien (pp. 40-65).

Freudenthal, H. (1983). Didactycal phenomenology of mathematical structures. Dordrecht, Holland: Reidel. Retrieved from http://gpdmatematica.org.ar/wp-content/uploads/2015/08/Freudenthal_Didactical_Phenomenolo gy_of_Mathematical_Structures1983.pdf

Golding, G. A., \& Kaput, J. J. (1996). A joint perspective on the idea of representation in learning and doing mathematics. In L. Steffe, P. Nesher, P. Cobb, G. A. Goldin \& B. Greer (Eds.), Theories of mathematical learning (pp. 397-430). Hillsdale, NJ: Erlbaum.

Gur, H. (2009). Trigonometry Learning. New Horizons in Education, 57(1), 67-80. Retrieved from https:/ / files.eric.ed.gov/fulltext/EJ860819.pdf

Hertel, J. T. (2013). Investigating the purpose of trigonometry in the modern sciences (Unpublished doctoral dissertation), Illinois State University, Illinois, IL.

Hiebert, J., \& Carpenter, T. P. (1992). Learning and teaching with understanding. In D.A. Grouws (Eds.), Handbook of research on mathematics teaching and learning: A project of the National Council of Teachers of Mathematics (pp. 65-98). New York: Macmillan. https:/ / doi.org/10.2307/749496

Kamber, D., \& Takaci, D. (2018). On problematic aspects in learning trigonometry. International Journal of Mathematical Education in Science and Technology, 49(2), 161-175. https:/ / doi.org/10.1080/0020739X.2017.1357846

Krippendorff, K. (1989). Content analysis. In E. Barnouw, G. Gerbner, W. Schramm, T. L. Worth, \& L. Gross (Eds.), International encyclopedia of communication (Vol. 1, pp. 403-407). New York, NY: Oxford University Press. Retrieved from http:/ / repository.upenn.edu/asc_papers/226

Lamon, S. J. (1995). Ratio and proportion: Elementary didactical phenomenology. In J.T. Sowder \& B.P. Schapelle (Eds.), Providing a foundation for teaching mathematics in the middle grades (pp. 167-198). Albany, NY: State University of New York.

Maor, E. (1998). Trigonometric delights. Princeton, NJ: Princeton University Press.

Marchi, D. J. (2012). A Study of Student Understanding of the Sine Function through Representations and the Process and Object Perspectives (Unpublished doctoral dissertation), The Ohio State University, Ohio. Retrieved from https:/ / etd.ohiolink.edu/!etd.send_file?accession=osu1343253667\&disposition=inline

Martín Fernández, E., Ruiz Hidalgo, J. F., \& Rico, L. (2016). Significado escolar de las razones trigonométricas elementales [Student's notions of elementary trigonometric ratios]. Enseñanza de las Ciencias, 34(3), 51-71. https://doi.org/10.5565/rev/ensciencias.1871

Ministerio de Educación y Ciencia (2007). Real Decreto 1467/2007, por el que se establece la estructura del bachillerato y se fijan sus enseñanzas mínimas. [Royal legilastive Decree 1467/2007, by which the structure of the baccalaureate is established and its minimum teachings are set], BOE, 266, 2007, 2nd November, pp. 45381-45477. 
Montiel Espinosa, G., \& Jácome Cortés, G. (2014). Significado trigonométrico en el professor [Trigonometric meaning in the teacher]. Boletim de Educação Matemática, 28(50), 1193-1216. https://doi.org/10.1590/19804415v28n50a10

Moore, K. C. (2012). Coherence, quantitative reasoning, and the trigonometry of students. Quantitative reasoning and mathematical modeling: A driver for STEM integrated education and teaching in context, 2, 75-92. Retrieved from http://www.uwyo.edu/wisdome/_files/documents/moore.pdf

Moore, K. C., \& LaForest, K. R. (2014). The circle approach to trigonometry. Mathematics Teacher, 107(8), 616-623. https://doi.org/10.5951/mathteacher.107.8.0616

Moore, K. C., LaForest, K. R., \& Kim, H. J. (2016). Putting the unit in pre-service secondary teachers' unit circle. Educational Studies in Mathematics, 92(2), 221-241. https:/ / doi.org/10.1007/s10649-015-9671-6

Morgan, C., \& Kynigos, C. (2014). Digital artefacts as representations: forging connections between a constructionist and a social semiotic perspective. Educational Studies in Mathematics, 85(3), 357-379. https:/ / doi.org/10.1007/s10649-013-9523-1

Orhun, N. (2004). Students' mistakes and misconceptions on teaching of trigonometry. Retrieved from http:/ / dipmat.math.unipa.it/ grim/AOrhun.PDF

Paoletti, T., Stevens, I. E., Hobson, N. L., Moore, K. C., \& LaForest, K. R. (2015). Pre-service teachers' inverse function meanings. In T. Fukawa-Connelly, N. Infante, K. Keene, \& M. Zandieh (Eds.), Proceedings of the Eighteenth Annual Conference on Research in Undergraduate Mathematics Education (pp. 853-867). Pittsburgh, PA: West Virginia.

Radford, L. (2003). Gestures, speech, and the sprouting of signs: A semiotic-cultural approach to students' types of generalization. Mathematical thinking learning, 57(1), 37-70. https:/ / doi.org/10.1207/S15327833MTL0501_02

Rico, L. (2009). Sobre las nociones de representación y comprensión en la investigación en educación matemática [On the notions of representation and understanding in mathematics education research], PNA, 4(1), 1-14. Retrieved from http:/ / funes.uniandes.edu.co/662/1/Rico2009Sobre.pdf

Rico, L., \& Moreno, A. (2016). Elementos de didáctica de la matemática para el profesor de secundaria [Mathematics didactic elements for the secondary school teacher]. Madrid, Spain: Ediciones Pirámide. Retrieved from https:/ / dialnet.unirioja.es / servlet/libro? codigo $=660283$

Sáenz-Ludlow, A. (2003). A collective chain of signification in conceptualizing fractions: A case of a fourth-grade class. The Journal of Mathematical Behavior, 22(2), 181-211. https:/ / doi.org/10.1016/S0732-3123(03)00019-1

Sevimli, E., \& Delice, A. (2012). The relationship between students' mathematical thinking types and representation preferences in definite integral problems. Research in Mathematics Education, 14(3), 295-296. https:/ / doi.org/10.1080/14794802.2012.734988

Shapiro, S. (1997). Philosophy of mathematics: Structure and ontology. Oxford, Uk: Oxford University Press.

Sickle, J. V. (2011). A history of trigonometry Education in the United States 1776-1990 (Unpublished doctoral dissertation), Combia Uniluversity, Nueva York, NY. https:/ / doi.org/10.7916/D8G166T7

Skemp, R. (1987). The psychology of learning mathematics, Hillsdale, NJ: Erlbaum Associates.

Steinbring, H. (1998). Elements of epistemological knowledge for mathematics teachers. Journal of Mathematics Teacher Education, 1(2), 157-189. https:/ / doi.org/10.1023/A:1009984621792

Steinbring, H. (2006). What makes a sign a mathematical sign? -An epistemological perspective on mathematical interaction. Educational Studies in Mathematics, 61(1-2), 133-162. https:/ / doi.org/10.1007/s10649-006-5892-z

Tavera, F., \& Villa Ochoa, J. A. (2016). Sobre las razones y las funciones trigonométricas: ¿Qué tratamiento hacen los libros de texto? [On the ratios and trigonometric functions: What treatment do textbooks do?]. Acta Latinoamericana de Matemática Educativa. Retrieved from http://200.24.17.68:8080/jspui/bitstream/ 123456789/2459/1/Tavera_Villa-ochoa_2016.pdf

Thompson, K. (2007). Student's understanding of trigonometry enhanced through the use of a real world problem: improving the instructional sequence (Unpublished doctoral dissertation), Illinois State University, Illinois, IL.

Thompson, P. W., Carlson, M. P., \& Silverman, J. (2007). The design of tasks in support of teachers' development of coherent mathematical meanings. Journal of Mathematics Teacher Education, 10(4-6), 415-432. https:/ / doi.org/10.1007/s10857-007-9054-8

Van den Heuvel-Panhuizen, M. (2003). The didactical use of models in realistic mathematics education: An example from a longitudinal trajectory on percentage. Educational studies in Mathematics, 54(1), 9-35. https:/ / doi.org/10.1023/B:EDUC.0000005212.03219.dc 
Van den Heuvel-Panhuizen, M. (2014). Didactical phenomenology (Freudenthal). In S. Lerman (Ed.), Encyclopedia of mathematics education (pp. 174-176). Heidelberg: Springer. https:/ / doi.org/10.1007/978-94-007-4978-8_49

Vergnaud G. (1990). La théorie des champs conceptuels, Recherches en Didactique des Mathématiques [Conceptuals Fields Theory, Research in Mathematical Didactics], 10(2.3), 133-170.

Vizmanos, J. R., Alcaide, F., Hernández, J., Moreno, M., \& Serrano, E. (2008). Matemáticas $1^{\circ}$ Bachillerato (Ciencias y Tecnologia) [Mathematics $1^{\text {st }}$ Baccalaureate (Science and Technology)]. Madrid, Spain: S.M.

Weber, K. (2005). Student's understanding of trigonometric functions. Mathematics Education Research Journal, 102(2), 144-147. Retrieved from https:/ / files.eric.ed.gov/fulltext/EJ747914.pdf

Weber, K. (2008). Teaching trigonometric functions: Lessons learned from research. Mathematics Teacher, 17(3), 91112. https:// doi.org/10.1007/BF03217423

Yiğit Koyunkaya, M. (2016). Mathematics education graduate students' understanding of trigonometric ratios. International Journal of Mathematical Education in Science and Technology, 47(7), 1028-1047. https:/ / doi.org/10.1080/0020739X.2016.1155774

Zhang, Y., \& Wildemuth, B. M. (2009). Qualitative analysis of content. In B. Wildemuth (Ed.), Applications of social research methods to questions in information and library science (pp. 222-231). Westport CT: Libraries Unlimited.

\section{http://www.ejmste.com}

